One-third of the recent British Medical Bulletin on influenza ${ }^{1}$ is on this aspect of the virus, including two complete articles on the chemistry of one surface component alone. Admittedly, this is the haemagglutinin, a glycoprotein which largely determines the pathogenicity of the virus. Nevertheless, it is now a far cry from the days when a distinguished virologist could write that "... what viruses do and how they do it is very much more important than what they are." Not surprisingly, what viruses are goes a long way to explaining what they do, and influenza virus is no exception. Its behaviour has for long puzzled virologists. The more or less sudden appearance of major new variants every few years seemed to have no reasonable genetic or biological explanation, even though it was accompanied by a more intelligible and less abrupt antigenic change of surface characters. The phenomenon of genetic recombination in influenza had certainly been observed in the laboratory in cells infected simultaneously with two strains of the virus. ${ }^{2}$ The puzzle was that the recombination rate was embarrassingly high compared with that of other viruses, and the ease with which a reassortment of genetic factors could occur seemed almost too good to be true.

Two decades of intensive work have done much to explain these features. Genetically, the influenza virus is best considered as a set of eight little RNA viruses-that is to say, eight pieces of RNA each coding for a peptide. These RNA moieties have some independence of expression within the cell-as has been known for years from the work, for example, of Scholtissek and $\operatorname{Rott}^{3}$ on avian influenza ${ }^{4}$ virus. Nevertheless, the RNA moieties are not independently viable, and they must work as a team, requiring each one of the eight members. This behaviour contrasts with, for example, mumps or measles or even a plant virus such as tobacco mosaic virus. All of these are, like influenza, RNA viruses, but the RNA behaves essentially as one large genetic and biochemical unit. The relative independence of action enjoyed by the eight little viruses which make up influenza means that, in a cell infected with two different strains of influenza (with two "teams" of eight in the same cell at one time), a reassortment of the players can occur. This process can be followed by observing and identifying, in particular, the haemagglutinin $(\mathrm{H})$ and also the neuraminidase $(\mathrm{N})$, both of them surface proteins. When recombination occurs, strains of influenza with differing $\mathbf{H}$ and N components "swap" with each other-or, to continue the terminology of the football field, transfer one or more players.

The World Health Organisation has proposed a nomenclature for the subtypes of $\mathrm{H}$ and $\mathrm{N}$ proteins, and there are now sixteen $\mathrm{H}$ and ten $\mathrm{N}$ subtypes known, making possible 160 combinations. Of these subtypes, five $\mathrm{H}$ and two $\mathrm{N}$ have been found in strains isolated from man, two of each from pigs, and two of each from horses. Interestingly, the largest variety is found in birds, especially domestic poultry and wild ducks. Several subtypes of influenza A may be circulating in the avian fauna of a single piece of water, and there may be two or even more subtypes infecting one duck at the same time. ${ }^{5}$

The sudden emergence of an influenza virus with a new $\mathrm{H}$ or $\mathrm{N}$ protein subtype (or both) on its surface demands an explanation, and the answer seems likely to be recombination of an existing strain in a duck, perhaps in a pig, or even in a horse. Direct transfer from an animal reservoir to man is another possibility, and the persistence of "old" strains in a reservoir of ducks or pigs could explain otherwise puzzling observations such as the reappearance of swine influenza (Hswl) in man and the recent emergence from retirement of an old combination such as $\mathrm{H} 1 \mathrm{~N} 1$ after 30 years. Though H1N1 has not been found contemporaneously in ducks, Shortridge $^{7}$ has recently reported the presence of $\mathrm{H} 2 \mathrm{~N} 2$ (absent from man for 10 years) in domestic ducks from southern China, and it would not be surprising if there were more influenzas, new and old, still to emerge from that country -where the ducks are said to outnumber the Chinese.

For years now the unpredictability of the major changes has combined with the steady drift of surface antigens within an $\mathrm{H}$ or $\mathrm{N}$ subtype to make influenza the despair of vaccine manufacturers. Their problems in trying to keep pace with new strains are all too familiar. Moreover, a recent publication of the results of a detailed study at a boys' boarding school ${ }^{8}$ suggests that those who were vaccinated were little better off (perhaps worse) after their first postvaccination encounter with the strain concerned. Once a new major strain difference ("shift") occurred they needed a completely fresh vaccine anyway. Improvement may, however, be possible through better ways of inactivating the virus or better ways of using adjuvants; and live vaccines may one day come into their own. Nevertheless, the prevailing mood is clearly one of qualified pessimism. So far as specific chemotherapy is concerned, the various compounds tried in hope have not yielded results that stand comparison with their counterparts in bacteriology. The cyclic primary amines of the amantadine series have a significant inhibitory effect, but in practical terms their use is limited by the need to give them prophylactically and the possibility of development of drug-resistant strains.

All these aspects are discussed in the British Medical Bulletin $^{1}$ issue on influenza. On reflection, perhaps we have one ground for encouragement: we can at least rest assured that, if the stalemate over influenza continues, it will not be because of untried moves.

\footnotetext{
British Medical Bulletin, 1979, 35, 1. (Published by the Medical Department, The British Council, 65, Davies Street, London W1Y 2AA.)

Burnet, F M, and Lind, P E, Australian fournal of Experimental Biology and Medicine, 1952, 30, 469.

${ }^{3}$ Scholtissek, C, and Rott, R, Virology, 1964, 22, 169.

${ }^{4}$ Schäfer, W, Zeitschrift für Naturforschung, 1955, 10b, 81.

5 Laver, W G, and Webster, R G, British Medical Bulletin, 1979, 35, 29.

Easterday, B C, in The Influenza Viruses and Influenza, ed E D Kilbourne, p 449. New York and London, 1975.

Shortridge, K F, Lancet, 1979, 1, 439.

${ }^{8}$ Hoskins, T W, et al, Lancet, 1979, 1, 33.
}

\section{Premature rupture of the membranes}

Premature rupture of the membranes is an inappropriate and ill-defined term. The phrase is commonly applied to any rupture of the membranes at any time before the onset of labour, regardless of the length of gestation. By this definition it occurs in $6 \%$ to $12 \%$ of pregnancies, but most of the babies are neither "premature" in terms of gestational age nor of low birth weight. For practical purposes a useful distinction may be drawn between rupture of the membranes occurring "prelabour" and "preterm".

Labour rapidly succeeds rupture of the membranes in most instances, but the latent period tends to be longer in patients further from term. In a prospective study ${ }^{1}$ of 1896 women with prelabour rupture of the membranes, labour ensued within 24 hours in $68 \%$ when the infant was mature $(>2500 \mathrm{~g}$ ) and in $42 \%$ when the infant was premature $(1000-2500 \mathrm{~g})$. By 
the 14 th day $3.3 \%$ of the mature group and $8 \cdot 1 \%$ of the premature group remained undelivered.

Fetal immaturity is by far the most important cause of perinatal mortality associated with preterm rupture of the membranes. For this reason a conservative management is often adopted in the hope of maintaining pregnancy as long as possible. Against the undoubted benefits of increased fetal maturity must be offset the hazard of intrauterine infection, which accounts for about $20 \%$ of all infant deaths after premature rupture of the membranes. ${ }^{12}$

Once the membranes have ruptured the adverse effect of time on the perinatal mortality rate is striking. The mortality rate doubles when the latent interval exceeds 24 hours and quadruples after 48 hours. $^{3}$ Early diagnosis is therefore important and delivery should be expedited whenever the fetus is thought to be sufficiently mature to survive independently.

Intrauterine infection rapidly occurs after rupture of the membranes, affecting $10 \%$ of pregnancies within 48 hours, $26 \%$ by 72 hours, and $40 \%$ of patients whose membranes have been ruptured longer than 72 hours. ${ }^{4}$ Unfortunately, we have no reliable means of knowing when the fetus is at risk from infection. In a prospective study ${ }^{2}$ of 60 patients with preterm rupture of the membranes, pathogens were recovered from vaginal or cervical swabs at some time during the latent period in 52. Frank infection was apparent in eight patients but only two had fever or tachycardia. Eight perinatal deaths were associated with infection but in none had there been clinical evidence of infection before delivery.

Opinions vary widely about the value of prophylactic antibiotics. In the 1960s several reports appeared in favour of antibiotics, ${ }^{35}$ claiming a reduction in the perinatal mortality rate and in maternal morbidity. Burchell ${ }^{3}$ found a reduction in perinatal deaths from 42.9 to 34.5 per 1000 when antibiotics were used. This improvement was due largely to a reduction in the number of neonatal deaths, but there was a much smaller reduction in the number of stillbirths. The study was retrospective, and unfortunately no reference was made to the type of antibiotics used or to any antibiotic treatment of the neonate. In a prospective, multicentre, double blind study ${ }^{1}$ about half of 1896 women with prelabour rupture of the membranes were given prophylactic dimethyl-chlortetracycline and half were given a placebo. All the babies were given penicillin and streptomycin at birth. A total of 1912 babies were delivered with a perinatal mortality rate of 38 per 1000 . In the mothers given prophylactic antibiotics the rate was 34 compared with 43 per 1000 in those who were not. Despite the excellent design of this study, chlortetracycline is an antibacterial drug which would no longer be chosen for use in obstetrics, and the conclusions drawn may well not apply to the other drugs. In a smaller prospective study ${ }^{2}$ of 25 patients with prelabour rupture of the membranes who received antibiotics before delivery three perinatal deaths occurred with evidence of infection. Among 35 patients who received no chemotherapy there were five perinatal deaths associated with infection.

These results provided little evidence of any substantial benefit from prophylactic antibiotic treatment, which is little used nowadays. Indeed, there are practical difficulties in administering effective doses of antibiotics for periods exceeding a week, and it is probably better to reserve antibiotic treatment for the neonate.

The management of rupture of the membranes depends, then, on the judicious use of induction of labour to strike a balance between the risks of fetal immaturity and those of infection associated with conservative management. Most authors recommend immediate induction of labour when the fetus is 34 or more weeks mature or is judged to weigh at least $2000 \mathrm{~g}$. Beyond this stage there is a $95 \%$ chance $^{6}$ of spontaneous labour starting within a week, and the added maturity gained is insufficient to justify the increased risk of infection associated with conservative management. Before 34 weeks there is a one-in-four chance of the pregnancy continuing for more than a week, and, as immaturity is the principle risk to the fetus at this stage, the balance of risks is tipped in favour of conservative management.

One bonus which may be gained when labour is delayed by 24 hours after rupture of the membranes is a decreased incidence of the respiratory distress syndrome in low-birthweight infants. ${ }^{7-10}$ This decrease is less apparent in babies born after 32 weeks or with a birth weight of over $1500 \mathrm{~g}$. Because of the high probability that labour will soon follow rupture of the membranes, there is much to recommend the routine administration of corticosteroids to all such patients when the gestational age is less than 34 weeks. If labour seems imminent the obstetrician should consider using concurrently a beta-mimetic drug, such as ritodrine, to delay birth for 24 hours or so while the corticosteroid takes effect.

${ }^{1}$ Lebherz, T B, et al, American fournal of Obstetrics and Gynecology, 1963, 87, 218.

2 Townsend, L, Aickin, D R, and Fraillon, J M G, Australia and New Zealand fournal of Obstetrics and Gynaecology, 1966, 6, 226.

3 Burchell, R C, American fournal of Obstetrics and Gynecology, 1964, 88, 251.

4 Fayez, J A, et al, Obstetrics and Gynecology, 1978, 52, 17.

5 Breese, M W, American Fournal of Obstetrics and Gynecology, 1961, 81, 1086.

- Gillibrand, P N, fournal of Obstetrics and Gynaecology of the British Commonwealth, 1967, 74, 678.

7 Yoon, J J, and Harper, R G, Pediatrics, 1973, 52, 161.

${ }^{8}$ Miller, J M, Pupkin, J M, and Crenshaw, C, American fournal of Obstetrics and Gynaecology, 1978, 132, 1.

9 Berkowitz, R L, Bonta, B W, and Warshaw, J E, American fournal of Obstetrics and Gynecology, 1976, 124, 712.

10 Bauer, C R, Stern, L, and Colle, E, Pediatrics, 1974, 53, 7. 